\title{
Trapping an Unusual Pentacoordinate Carbon Atom in a Neutral Trialuminum Complex
}

\author{
Nery Villegas-Escobar, ${ }^{*[a]}$ Javier Martínez, ${ }^{[b]}$ Ricardo A. Matute, ${ }^{[a, c]}$ Sebastián Saltarini, ${ }^{[d]}$ Constantin G. \\ Daniliuc, ${ }^{\left[{ }^{[e]}\right.}$ Lutz H. Gade, ${ }^{[f]}$ and René S. Rojas*[d]
}

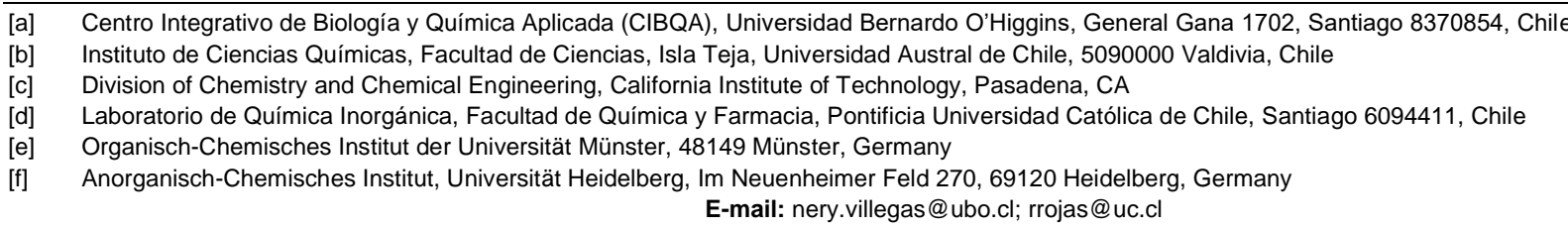

Supporting information for this article is given via a link at the end of the document.

\begin{abstract}
A neutral trialuminum complex incorporates a pentacoordinate carbon through a methylidene bridge linking the three metal atoms. The rigid electron-deficient $\mathrm{Al}_{3}$ core stabilizes the hypercoordinate carbon atom resulting in the shortest equatorial $\mathrm{Al}$ $\mathrm{C}$ distance reported for such $\mathrm{Al}_{3}-\left(\mu^{3}-\mathrm{CH}_{2}\right)$ unit.
\end{abstract}

Carbon atoms are commonly found as di-, tri-, or tetracoordinate by obeying the octet rule through the formation of formal 2-electron (2e) covalent bonds. Although its heavier group 14 congeners are known to exhibit coordination numbers greater than four, hypercoordinate carbon atoms are very rare.

It is widely accepted that a central pentacoordinate carbon atom is found at the transition state (TS) within the Walden inversion of an $S_{N} 2$ reaction. ${ }^{[1-4]}$ However, there is no consensus concerning a potential hypervalent nature of such a short-lived entity, ${ }^{[5,6]}$ not the least because the bonds in the reaction axis lose covalent character at the TS with concomitant charge build-up. ${ }^{[6]}$ On the other hand, there are computational studies that indicate that stationary structures having a pentacoordinate carbon atom resembling the $\mathrm{S}_{\mathrm{N}} 2$ TS may be stabilized by electropositive atoms such as $\mathrm{Ga}$ and $\mathrm{Al} .{ }^{[7]}$

Although cationic $\mathrm{CR}_{5}{ }^{+}$systems have been confirmed experimentally ${ }^{[8-10]}$ they are short-lived, even at low temperatures. Bickelhaupt and co-workers rationalized that carbon is more limited to exhibit coordination numbers $>4$ as compared to its group 14 analogs primarily due to its smaller size ("ball in a box" model). ${ }^{[11]}$

A rational way of trapping pentacoordinate carbon atoms is by employing rigid molecular scaffolds. ${ }^{[2,12,13]}$ Interestingly, planar pentacoordinate carbon atoms are often found in strained molecular clusters and solids, and they have been an active niche for theoretical predictions. ${ }^{[14-24]}$ The search for pentacoordinate $C$ atoms in organic molecules started in 1919 by Staudinger, ${ }^{[25]}$ until, in 1999, the first such species having a strained anthracene backbone was prepared and characterized by X-ray diffraction. ${ }^{[1,3]}$ Subsequently, such hypercoordinate carbon centers have been successfully prepared using ligands with various degrees of rigidity. ${ }^{[2]}$ Notably, it has even been possible to obtain molecules with formally hexacoordinate carbon centres. ${ }^{[4]}$

Despite the challenging nature of accessing compounds with pentacoordinate carbon atoms, they have been found as methylidene $\left(\mathrm{CH}_{2}^{2-}\right)$ units in highly polar organometallics such as in rare earth elements complexes (see ref. ${ }^{[26]}$ and references therein) or mixed rare earth $\mathrm{Al}$ complexes. ${ }^{[27-35]}$ However, there are only a few reports of methylidenes coordinated solely to aluminium in such mixed-metal polynuclear complexes. ${ }^{[36-38]} \mathrm{By}$ the reaction of an $\mathrm{N}$-heterocyclic carbene $(\mathrm{NHC})$ with $\mathrm{Al}\left(\mathrm{CH}_{3}\right)_{3}$ Dagorne and co-workers obtained an abnormal $\mathrm{NHC}-\mathrm{Al}\left(\mathrm{CH}_{3}\right)_{3}$ species, which was found to further react with $\mathrm{Al}\left(\mathrm{CH}_{3}\right)_{3}$ producing a thermally unstable salt incorporating the $\mathrm{Al}_{3}-\left(\mu^{3}-\mathrm{CH}_{2}\right)$ moiety which decomposed in benzene solution. ${ }^{[39]}$ In the system reported by Dagorne and co-workers in 2006 the methylidene group attached to the three $\mathrm{Al}$ atoms is supported in a rigid molecular scaffold, but a rather flexible environment. A mechanistic model for the formation of the various species involved in this transformation was reported along with their DFT modelled energetics and bonding properties.

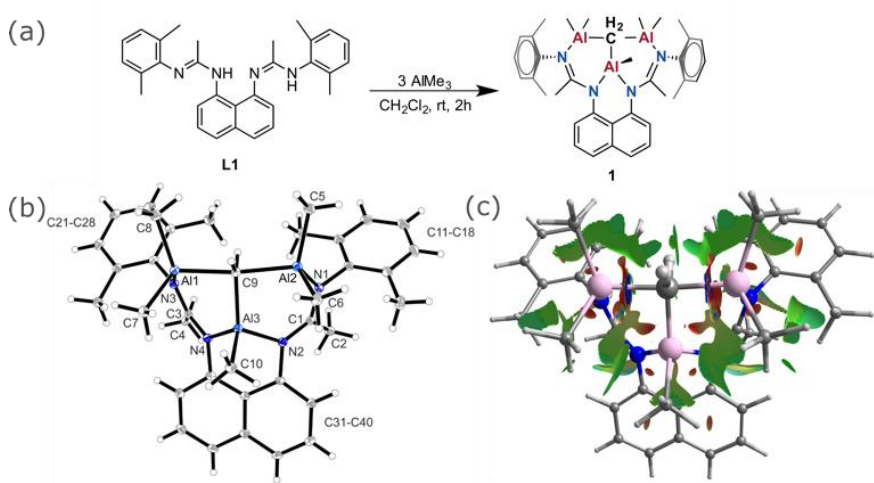

Figure 1. (a) Synthesis of trimetallic aluminum complex 1. (b) Crystal structure of 1 , with thermal ellipsoids shown with $30 \%$ probability. (c) Noncovalent interaction $(\mathrm{NCl})$ index for complex 1.

In this work, we report the synthesis and characterization of a novel neutral trinuclear aluminum complex (1), which exhibits a pentacoordinate carbon atom along with a detailed theoretical discussion of the bonding within the molecule. The central carbon of the formally dianionic methylidene $\mathrm{CH}_{2}{ }^{2-}$ unit is "trapped" by an array of aluminum atoms held in place by bisamidinato ligands with a rigid naphthalene backbone. Complex 1 was obtained in quantitative yield (>99\%) by reaction of 1 equiv. of bis(amidine)naphthalene ligand precursor (L1) with three equiv. of $\mathrm{AlMe}_{3}$ in $\mathrm{CH}_{2} \mathrm{Cl}_{2}$ at room temperature (Figure 1a). Upon washing the crude product with hexane and recrystallization from $\mathrm{CH}_{2} \mathrm{Cl}_{2}$ by toluene 
vapor diffusion, pale orange crystals of $P 2_{1} / n$ space group symmetry were obtained which were suitable for $X$-ray diffraction.

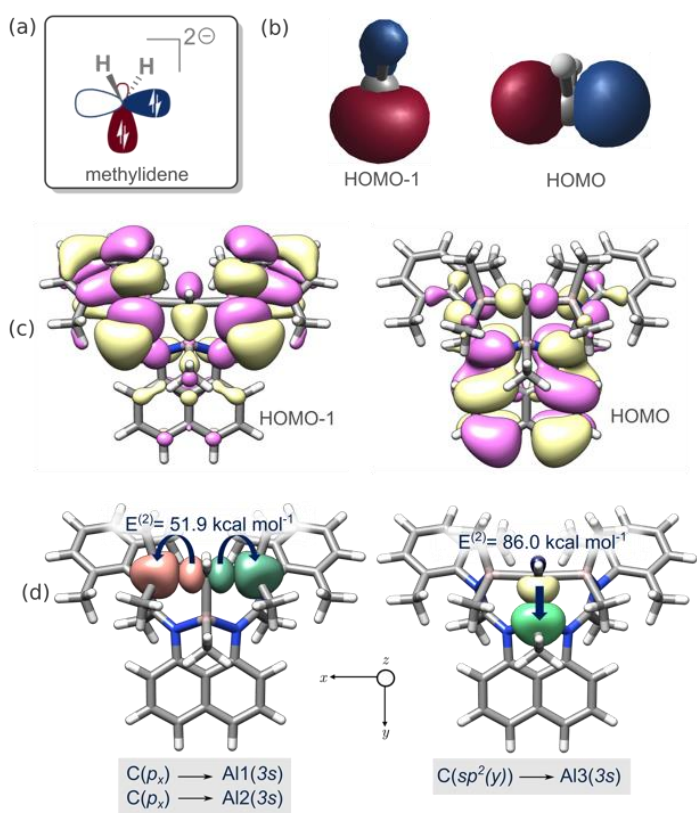

Figure 2. (a) Schematic representation of methylidene $\mathrm{CH}_{2}^{2-}$ (b) highest occupied molecular orbital (HOMO) and lowest unoccupied molecular orbital (LUMO) for isolated $\mathrm{CH}_{2}{ }^{2-}$ obtained with an isosurface of 0.1 a.u. (c) $\mathrm{HOMO}$ and LUMO for complex 1 . Isosurfaces were rendered at 0.01 a.u. (d) donor-acceptor NBO orbitals with associated stabilization energies $\left(E^{(2)}\right)$.

The molecular structure of complex 1 was characterized in solution by NMR spectroscopy $\left({ }^{1} \mathrm{H}\right.$ NMR, ${ }^{13} \mathrm{C}\left\{{ }^{1} \mathrm{H}\right\}$ NMR, ${ }^{1} \mathrm{H}$ NOESY-1D, ${ }^{1} \mathrm{H}-{ }^{13} \mathrm{C} g$-HSQC). The ${ }^{1} \mathrm{H}$ NMR spectrum of this compound shows the disappearance of the $\mathrm{N}-\mathrm{H}$ signal of the amidine precursor ${ }^{[40]}$, while the ${ }^{1} \mathrm{H}$ and ${ }^{13} \mathrm{C}\left\{{ }^{1} \mathrm{H}\right\}$ NMR resonance patterns corroborate the presence of an approximate plane of symmetry in the molecule (approximate $C_{s}$ point group). Notably, characteristic sets of signals are observed between -0.5 and -1.3 ppm in the ${ }^{1} \mathrm{H}$ NMR spectrum and between -4.0 and -8.0 ppm in the ${ }^{13} \mathrm{C}$ NMR which correspond to the methyl groups attached to the aluminum atoms (see Supporting Information). The key resonance of the pentacoordinate $\mathrm{CH}_{2}$-bridge appeared at 0.26 ppm and $-0.56 \mathrm{ppm}$ in the ${ }^{1} \mathrm{H}$ and ${ }^{13} \mathrm{C}\left\{{ }^{1} \mathrm{H}\right\}$ NMR spectra, respectively.

The molecular structure of complex 1 determined by X-ray diffraction is shown in Figure 1b. It reveals the presence of the pentacoordinate carbon atom, methylidene $\left(\mathrm{CH}_{2}{ }^{2-}\right)$, interacting with the three aluminum atoms in a slightly distorted trigonal bipyramidal geometry. The methylidene carbon atom is coplanar with the $\mathrm{Al}$ atoms with a dihedral $\phi(\mathrm{Al} 1-\mathrm{Al} 3-\mathrm{Al} 2-\mathrm{C} 9)$ of $-0.3^{\circ}$. Whereas the $\theta(\mathrm{Al} 3-\mathrm{C} 9-\mathrm{H} 9 \mathrm{~A})$ and $\theta(\mathrm{Al} 3-\mathrm{C} 9-\mathrm{H} 9 \mathrm{~B})$ angles of $122.1(1)^{\circ}$ and $128.2(2)^{\circ}$ differ from the ideal $120^{\circ}$ for the equatorial substituents in a trigonal bipyramid, the axial Al1-C9-Al2 array is near-linear $\left(173.1(1)^{\circ}\right)$. Notably, the Al3-C9 bond (1.958(2) $\AA$ ) is shorter than Al1-C9 and Al2-C9 (2.100(2) and $2.098(2) \AA$, respectively), which suggest a stronger binding of $\mathrm{Al} 3$ with the carbon bridge and is consistent with the interpretation of the axial bonding as being best represented by a 3-centre-2electron (3c-2e) model (vide infra). The Al3-C9 bond in complex 1 is to our knowledge the shortest $\mathrm{Al}-\mathrm{C}$ distance found in an $\mathrm{Al}_{3}$ -
$\left(\mu^{3}-\mathrm{CH}_{2}\right)$ system in any structural environment observed to date $^{[36-39,41]}$ and leads to the deviation of the axial Al1-C9-Al2 angle from linearity (see Table S5 in Supporting Information).

For the structurally equivalent axial Al1-C9 and Al2-C9 bonds, a Mayer bond order (MBO) of 0.436 was found, while the stronger bond Al3-C9 bond is characterized by a bond order of 0.550 . Although most polar bonding interactions in transition metal and main group systems give rise to reduced bond orders, the analysis shows that $\mathrm{Al}-\mathrm{C9}$ bonds possess a considerable degree of covalency. The natural charge of the carbon atom is $1.824|\mathrm{e}|$, confirming the interpretation of the methylene unit as a formally dianionic $\mathrm{CH}_{2}{ }^{2-}$. The latter is surrounded in a positively charged core formed by the electron-deficient $\mathrm{Al}$ atoms with charges of $+1.831|\mathrm{e}|$ for $\mathrm{Al} 1$ and $\mathrm{Al} 2$, and $+1.952|\mathrm{e}|$ for $\mathrm{Al} 3$, indicating a high degree of bond polarization, and a resulting enhanced electrostatic interaction between the $\mathrm{Al}$ and $\mathrm{C}$ atoms. The latter is corroborated by a blueish region in the $\mathrm{NCl}$ isosurface (Figure 1c) which also represents the mismatch in electron density among $\mathrm{Al} 3$ and the $\mathrm{Al} 1$ and $\mathrm{Al} 2$ atoms. Any long-range interaction among $\mathrm{Al}$ atoms [Al1-Al3 2.979(1) $\AA$ and Al2-Al3 $2.931(1) \AA]$ is compensated by a steric repulsion indicated by a red $\mathrm{NCl}$ isosurface (Figure 1c).

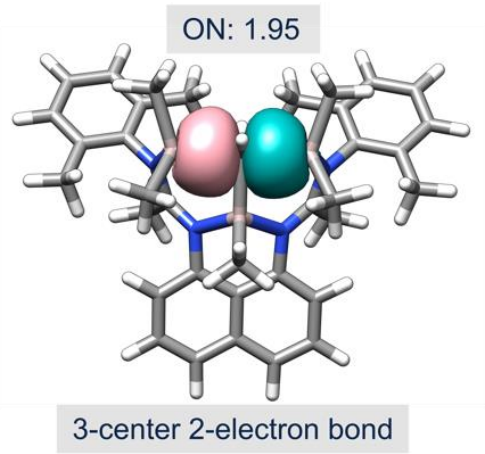

Figure 3. Representation of the 3c-2e bond responsible for the Al1-C9-Al2 interaction obtained by adaptive natural density partitioning (AdNDP) analysis. Occupation number $(\mathrm{ON})$ is displayed.

The fundamental orbital interactions accounting for the stability of the pentacoordinate $\mathrm{C}$ atom are given in Fig. $2 \mathrm{a}$, while HOMO-1 and HOMO isosurfaces for the isolated $\mathrm{CH}_{2}{ }^{2-}$ are depicted in Figure $2 \mathrm{~b}$. Bonding in the methylidene $\mathrm{CH}_{2}{ }^{2-}$ fragment may be viewed as based on three co-planar and hybridized $s p^{2}$ orbitals, two of them forming bonds with hydrogen atoms, while the remaining containing an electron pair that interacts with $\mathrm{Al} 3$. This gives rise to the higher $\mathrm{BO}$ observed for the equatorial Al3-C9 interaction. Conversely, the non-hybridized $p_{x}$ orbital, also containing an electron pair, allows a symmetric interaction with Al1 and Al2 which is best described as a 3c-2e, as confirmed by adaptive natural density partitioning (AdNDP) ${ }^{[42]}$ analysis (see Figure 3) and in agreement with proportional MBOs. In Fig. 2c, the corresponding $\mathrm{HOMO}$ and $\mathrm{HOMO}-1$ orbitals for complex 1 also exhibit the dominant $s p^{2}$ and $p_{x}$ orbital character on the pentacoordinate carbon atom, observed for the isolated methylidene moiety. The second-order NBO results are summarized in Figure 2d. Both Al1 and Al2 are bonded to $\mathrm{CH}_{2}$ through a donation from the non-hybridized $2 p_{x}$ orbital in $\mathrm{C}$ to the empty $3 s$ orbital in the corresponding aluminum atoms amounting to stabilization energy of $51.9 \mathrm{kcal} \mathrm{mol}^{-1}$. However, a stronger 
interaction, responsible for the higher covalent nature of the $\mathrm{Al} 3-\mathrm{C}$ bond, corresponds to $86.0 \mathrm{kcal} \mathrm{mol}^{-1}$ from the hybridized $s p^{2}$ orbital on carbon to the $3 s$ orbital in Al3.

Topological analyses based on the quantum theory of atoms in molecules (QTAIM) ${ }^{[43,44]}$ revealed the formation of five bond critical points (BCPs). However, the low electron density and positive values for the Laplacian of the electron density at the $\mathrm{BCPs}$ for the $\mathrm{Al}-\mathrm{C}$ contacts reveal that these interactions are dominated by significant electrostatic contributions and would contradict an interpretation in terms of hypervalency (see Supporting Information). These results are also in agreement with those reported by Dagorne and co-worker ${ }^{[41]}$ for the less rigid, charged $\mathrm{Me}_{3} \mathrm{Al}\left(\mu^{3}-\mathrm{CH}_{2}\right)\left(\mathrm{AlMe}_{2}\right)_{2}\left(\mu^{2}-\mathrm{CH}_{3}\right)^{-}$unit, both studies thus complementing each other in a full understanding of aluminum stabilized methylidene moieties.
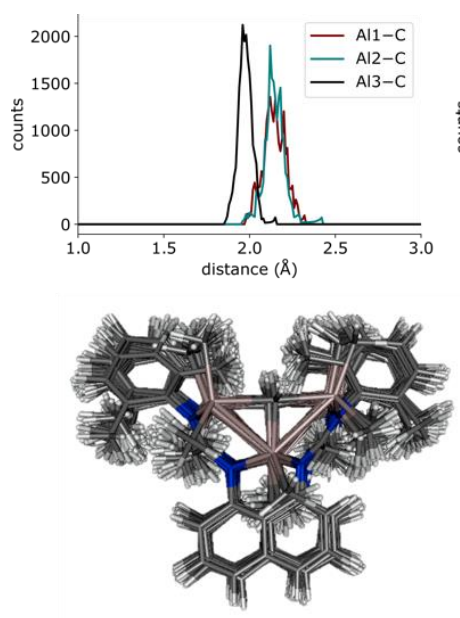
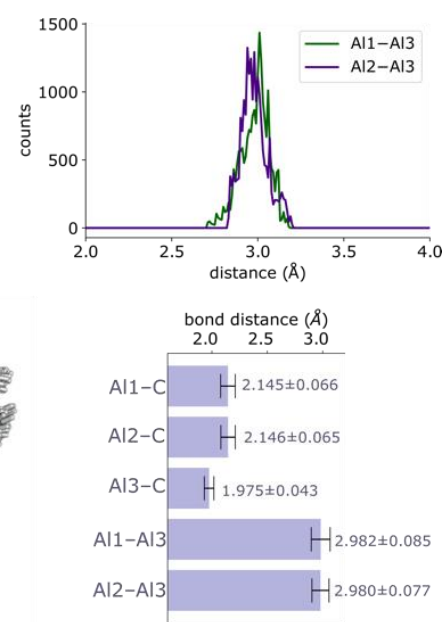

Figure 4. Geometrical results from dynamical trajectories of complex 1. Distribution of relevant bond distances (upper panel) and dynamical bond distances obtained through the trajectory calculation (lower panel).

Finally, to characterize the stability of the trinuclear aluminum complex tied together by the pentacoordinate $\mathrm{CH}_{2}$ unit, and to probe the dynamic behavior of a vibrationally excited $\mathrm{Al}_{3}$ $\left(\mu^{3}-\mathrm{CH}_{2}\right)$ system over time, reaction trajectories using atom density molecular propagation $(\mathrm{ADMP})^{[45-47]}$ dynamics were computed for a time frame of $2.000 \mathrm{fs}$, getting a total of 20.000 conformations that were used for statistics. During the simulation, no disruption of the complex was observed with the loss of the pentacoordinate carbon atom, revealing the enhanced kinetic stability of complex 1, which was found to be stable at $298 \mathrm{~K}$. Structural parameters extracted from the reaction dynamics are represented in Figure 4. In the upper panel, the distribution of distances is shown for both the Al-C (left) and Al-Al (right) interactions and confirms that the $\mathrm{Al} 3-\mathrm{C} 9$ bond remains the strongest interaction of the three $\mathrm{Al}-\mathrm{C}$ contacts with average interatomic distances of $1.975 \pm 0.066 \AA$ ( $1.978 \AA$ in the optimized complex), while the Al1 and Al2 interactions with methylidene are close to $2.146 \AA$ ( $2.132 \AA)$, with a wider distribution in comparison with the equatorial Al3. Notably, the average interatomic distances between the three $\mathrm{Al}$ atoms were found to be relatively stable at around $2.980 \AA(2.957 \AA)$. Most importantly, the pentacoordinate carbon atom is conserved all along the reaction trajectory thanks to the rigid aluminum infrastructure, strong orbital donor-acceptor interactions, and supported by stabilizing long-range interactions between the $\mathrm{Al}$ atoms. On the other hand, the peripheral $\mathrm{Ph}$ rings and the $\mathrm{CH}_{3}$ group attached to the central Al3 undergo significant structural variations (see molecular overlap in Figure 4).

In conclusion, the prepared neutral trialuminum complex $\mathbf{1}$ possesses a rigid aluminum core that helps retain a rare pentacoordinate carbon atom in position, strongly bonded through stabilizing $2 p_{x}$ and $s p^{2}$ donations from the $C$ atom to the $3 s$ orbital in Al. The Al1-C-Al2 is best described as a 3c-2e bond, the carbon atom thus not being truly pentavalent.

\section{Acknowledgements}

This work was supported by FONDECYT, Project No. 1200748. N.V.E acknowledges financial support from Fondecyt-ANID Postdoctorado Grant 3210532. J.M. acknowledges financial support from Fondecyt-ANID Postdoctorado project 3180073. R.A.M. acknowledges financial support from FONDECYT Grant 1181260. Powered@NLHPC: This research was partially supported by the supercomputing infrastructure of the NLHPC (ECM-02). This research was supported by the high-performance computing system of PIDi-UTEM (SCC-PIDiUTEM FONDEQUIP-EQM180180).

Keywords: pentacoordinate carbon $\cdot$ methylidene $\cdot$ trialuminium complex $\cdot \mathrm{DFT} \cdot$ bonding

[1] K. Akiba, M. Yamashita, Y. Yamamoto, S. Nagase, J. Am. Chem Soc. 1999, 121, 10644-10645.

K. Y. Akiba, Y. Moriyama, M. Mizozoe, H. Inohara, T. Nishii, Y. Yamamoto, M. Minoura, D. Hashizume, F. Iwasaki, N. Takagi, K. Ishimura, S. Nagase, J. Am. Chem. Soc. 2005, 127, 5893-5901. M. Yamashita, Y. Yamamoto, K. Y. Akiba, D. Hashizume, F. Iwasaki, N. Takagi, S. Nagase, J. Am. Chem. Soc. 2005, 127, 4354-4371.

[4] T. Yamaguchi, Y. Yamamoto, D. Kinoshita, K. Y. Akiba, Y. Zhang C. A. Reed, D. Hashizume, F. Iwasaki, J. Am. Chem. Soc. 2008 130, 6894-6895

[5] F. M. Bickelhaupt, C. F. Guerra, N. S. Zefirov, Mendeleev Commun 2010, 20,72-73.

[6] M. C. Durrant, Chem. Sci. 2015, 6, 6614-6623.

[7] Y.-B. Wu, Y.-Q. Li, H. Bai, H.-G. Lu, S.-D. Li, H.-J. Zhai, Z.-X. Wang, J. Chem. Phys. 2014, 140, 104302.

[8] J. W. Chinn, R. J. Lagow, J. Am. Chem. Soc. 1984, 106, 36943695.

[9] E. D. Jemmis, J. Chandrasekhar, E. U. Wuerthwein, P. von R Schleyer, J. W. Chinn, F. J. Landro, R. J. Lagow, B. Luke, J. A. Pople, J. Am. Chem. Soc. 1982, 104, 4275-4276.

[10] J. Z. Dávalos, R. Herrero, J. L. M. Abboud, O. Mó, M. Yáñez, Angew. Chemie - Int. Ed. 2007, 46, 381-385.

[11] S. C. A. H. Pierrefixe, C. F. Guerra, F. M. Bickelhaupt, Chem. - A Eur. J. 2008, 14, 819-828.

[12] T. R. Forbus, J. J. C. Martin, J. Am. Chem. Soc. 1979, 101, 50575059.

[13] J. C. Martin, Science (80-. ). 1983, 221, 509-514

[14] Z. X. Wang, P. Von Ragué Schleyer, Science (80-. ). 2001, 292 2465-2469.

[15] Y. Pei, W. An, K. Ito, P. V. R. Schleyer, C. Z. Xiao, J. Am. Chem. Soc. 2008, 130, 10394-10400.

[16] L. Leyva-Parra, L. Diego, O. Yañez, D. Inostroza, J. Barroso, A. Vásquez-Espinal, G. Merino, W. Tiznado, Angew. Chemie Int. Ed. 2021, 60, 8700-8704.

[17] R. Grande-Aztatzi, J. L. Cabellos, R. Islas, I. Infante, J. M. Mercero, A. Restrepo, G. Merino, Phys. Chem. Chem. Phys. 2015, 17, 46204624.

[18] Y. Wang, F. Li, Y. Li, Z. Chen, Nat. Commun. 2016, 7, 1-7.

[19] Z. hua Cui, V. Vassilev-Galindo, J. Luis Cabellos, E. Osorio, M. Orozco, S. Pan, Y. hong Ding, G. Merino, Chem. Commun. 2017 53, 138-141. 
[20] S. Pan, J. L. Cabellos, M. Orozco-Ic, P. K. Chattaraj, L. Zhao, G. Merino, Phys. Chem. Chem. Phys. 2018, 20, 12350-12355.

[21] V. Vassilev-Galindo, S. Pan, K. J. Donald, G. Merino, Nat. Rev. Chem. 2018, 2, 0114

[22] E. Ravell, S. Jalife, J. Barroso, M. Orozco-Ic, G. Hernández-Juárez, F. Ortiz-Chi, S. Pan, J. L. Cabellos, G. Merino, Chem. - An Asian J. 2018, 13, 1467-1473.

[23] J. C. Guo, L. Y. Feng, J. Barroso, G. Merino, H. J. Zhai, Chem. Commun. 2020, 56, 8305-8308

[24] O. Yañez, R. Báez-Grez, J. Garza, S. Pan, J. Barroso, A. VásquezEspinal, G. Merino, W. Tiznado, ChemPhysChem 2020, 21, 145148.

[25] K.-Y. Akiba, Organo Main Gr. Chem. 2011, 251-268.

[26] J. Kratsch, P. W. Roesky, Angew. Chemie - Int. Ed. 2014, 53, 376383. [27] J. E. Kickham, F. Guérin, D. W. Stephan, J. Am. Chem. Soc. 2002,

[28] L. C. H. Gerber, E. Le Roux, K. W. Törnroos, R. Anwander, Chem. A Eur. J. 2008, 14, 9555-9564.

[29] J. Scott, H. Fan, B. F. Wicker, A. R. Fout, M. H. Baik, D. J. Mindiola J. Am. Chem. Soc. 2008, 130, 14438-14439.

[30] D. Bojer, A. Venugopal, B. Neumann, H. G. Stammler, N. W. Mitzel, Angew. Chemie - Int. Ed. 2010, 49, 2611-2614

[31] G. Meyer, Angew. Chemie - Int. Ed. 2010, 49, 3116-3118.

[32] D. Bojer, A. Venugopal, A. Mix, B. Neumann, H. G. Stammler, N. W. Mitzel, Chem. - A Eur. J. 2011, 17, 6248-6255

[33] D. Bojer, B. Neumann, H. G. Stammler, N. W. Mitzel, Chem. - A Eur. J. 2011, 17, 6239-6247.

[34] D. Bojer, B. Neumann, H. G. Stammler, N. W. Mitzel, Eur. J. Inorg Chem. 2011, 2, 3791-3796.

[35] W. Huang, C. T. Carver, P. L. Diaconescu, Inorg. Chem. 2011, 50 978-984.

[36] A. Herzog, H. W. Roesky, Z. Zak, M. Noltemeyer, Angew. Chemie Int. Ed. English 1994, 33, 967-968.

[37] A. Herzog, H. W. Roesky, F. Jäger, A. Steiner, M. Noltemeyer Organometallics 1996, 15, 909-917.

[38] H. M. Dietrich, J. W. Ziller, R. Anwander, W. J. Evans, Organometallics 2009, 28, 1173-1179.

[39] A. L. Schmitt, G. Schnee, R. Welter, S. Dagorne, Chem. Commun 2010, 46, 2480-2482.

[40] S. Saltarini, N. Villegas-Escobar, J. Martínez, C. G. Daniliuc, R. A Matute, L. H. Gade, R. S. Rojas, Inorg. Chem. 2021, 60, 11721182.

[41] G. Schnee, D. Specklin, J. P. Djukic, S. Dagorne, Organometallics 2016, 35, 1726-1734

[42] D. Y. Zubarev, A. I. Boldyrev, Phys. Chem. Chem. Phys. 2008, 10, 5207-5217.

[43] R. F. W. Bader, Acc. Chem. Res. 1985, 18, 9-15

[44] R. F. W. Bader, Chem. Rev. 1991, 91, 893-928.

[45] S. S. lyengar, H. B. Schlegel, J. M. Millam, G. A. Voth, G. E.

Scuseria, M. J. Frisch, J. Chem. Phys. 2001, 115, 10291.

[46] H. B. Schlegel, J. M. Millam, S. S. lyengar, G. A. Voth, A. D

Daniels, G. E. Scuseria, M. J. Frisch, J. Chem. Phys. 2001, 114, 9758-9763.

[47] H. B. Schlegel, S. S. lyengar, X. Li, J. M. Millam, G. A. Voth, G. E. Scuseria, M. J. Frisch, J. Chem. Phys. 2002, 117, 8694-8704. 